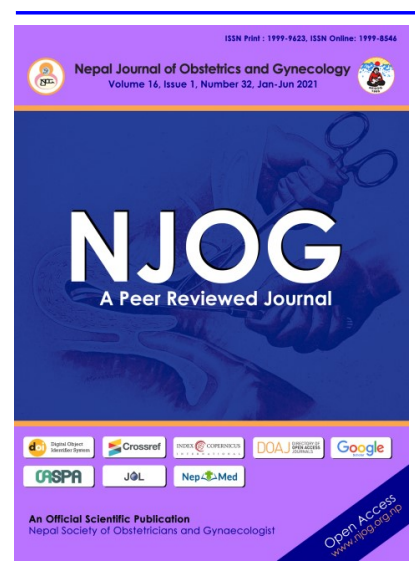

CORRESPONDENCE

Surendra Koju

Department of Pathology, Kathmandu University Hospital, Dhulikhel, Nepal

Email:

suren.koju@gmail.com; Phone: +977-9841791258

Received: December, 2020 Accepted: May 1, 2021

\section{Citation:}

Koju S, Tamrakar SR, Shankhadev R. Study of Semen Analysis Patterns in Male Partner of Infertile Couple Attending Tertiary Level Hospital of Nepal. Nep J Obstet Gynecol. 2021;16(32):57-60. DOI: https://doi.org/10.3126/ njog.v16i1.37520

\title{
Study of Semen Analysis Patterns in Male Partner of In- fertile Couple Attending Tertiary Level Hospital of Nepal
}

\author{
Surendra Koju ${ }^{1}$, Suman Raj Tamrakar ${ }^{2}$, Ramita Shankhadev ${ }^{1}$ \\ ${ }^{1}$ Department of Pathology, Dhulikhel Hospital - Kathmandu University \\ Hospital \\ ${ }^{2}$ Department of Obstetrics \& Gynecology, Dhulikhel Hospital - Kath- \\ mandu University Hospital
}

\section{ABSTRACT}

Aims: The aim of this study is to analyze the pattern of semen abnormality in male partner of infertile couple in Nepal.

Methods: A retrospective study of semen sample of male partner of infertile couple analyzed in Department of pathology, Dhulikhel Hospital from January 2014 to December 2018. All semen samples were processed and analyzed according to methods and standards outlined by World Health Organization laboratory manual for the examination and processing of human semen 2010.

Results: A total of 520 semen samples were analyzed. Our study shows 221 (44\%) abnormal for different semen parameters and asthenozoospermia $(39.3 \%)$ is the most common abnormality followed by azoospermia $(28.8 \%)$, Oligoasthenozoospermia (17.9\%), Oligozoospermia (8.7 \%), Oligoasthenoteratozoospermia (3.5\%) and teratozoospermia (1.8\%).

Conclusions: Abnormal semen parameters remain significant causes in overall infertility in our set up with asthenozoospermia and azoospermia were common abnormalities in male partner. Semen analysis is an inevitable tool for evaluation of infertility in male partner. Further study is required to find out the possible etiologies of male infertility for holistic management of infertility.

Keywords: azoospermia; infertility; oligospermia; semen

\section{INTRODUCTION}

Infertility is inability to conceive even after one year of regular and adequate sexual intercourse without use of any contraceptive tools. ${ }^{1}$ Prevalence of infertility is about $8-12 \%$ in world and $40-50 \%$ of cases of infertility are due to male partner in infertile couple. , $^{2,3}$ Infertility is very sensitive issue in country with patriarchal society. Most of the time female partner is blamed and punished for it; and male partners are not usually evaluated during infertility evaluation thus underestimating male factor infertility. ${ }^{4}$ Actually male factors are also equally responsible for infertility and semen analysis is an indispensible investigation in a couple with infertility. Semen analysis considered as primary and standard technique to assess male infertility. ${ }^{5,6}$ So, a proper interpretation of semen parameters can be effective tool in managing the male factor infertility. ${ }^{7}$
Most of the time, the exact etiology of male infertility is unknown. Few known factors for the male infertility are sexually transmitted disease, reproductive tract infection, endocrine disturbance, immunological problem, sexual dysfunction and ejaculatory problem. Oligozoospermia is associated with environment and lifestyle factors like chemical exposures, pesticide exposures, smoking, alcoholism, stress and obesity. ${ }^{8,9}$ This study will help in finding out the prevalence of male factor and nature of abnormal semen analysis pattern in infertile couple attending tertiary level hospital of Nepal.

\section{METHODS}

This is a retrospective study of seminal fluid of infertile couple attending Obstetrics \& Gynecology Department of Dhulikhel Hospital from January 2014 to December 
2018. Ethical approval was obtained from Institutional Review Committee (IRC) of Kathmandu University School of Medical Sciences (KUSMS).

Semen samples were collected in a sterile universal plastic container by masturbation after 3 days of sexual abstinence and the samples were delivered within one hour of semen collection. Semen analysis was done in the Department of Pathology, Dhulikhel Hospital. All semen samples were processed and performed according to methods and standards outlined by World Health Organization laboratory manual for the examination and processing of human semen 2010.

Different parameters like volume, $\mathrm{pH}$, viscosity, liquefaction, sperm concentration, motility and morphology were assessed. Results of Semen analysis were analyzed based on reference value of World Health Organization (WHO), 2010. Data were analyzed using SPSS16.0 version. The data were analyzed for frequency and mean \pm Standard deviation calculated for total sperm concentration, volume, progressive motility, immotility and age of male partner. 95\% confidence interval was calculated for proportions and for means. Mean value were compared for statistical significant using t-test with the level of significance set at $p<0.05$.

\section{RESULTS}

A total of 520 semen samples were studied with $78.5 \%$ primary and $21.5 \%$ secondary infertility; 291 (56\%) were normozoospermia and $221(44 \%)$ abnormal for different semen parameters.

Age range was 19-59 (30.3 \pm 5.3$)$ years and majority $(55.6 \%)$ at $21-30$ years age group. By ethnicity, $36.9 \%$ were Brahmin-Chhetris followed by Newars (32.1\%) and other janajati (21.5\%) [Table-1].

Table-1: Demographic characteristics of male infertile partners $(\mathrm{N}=520)$

\begin{tabular}{llcc}
\hline & Parameters & $\mathrm{N}$ & $(\%)$ \\
\hline Types of & Primary infertility & 408 & 78.5 \\
infertility & Secondary infertility & 112 & 21.5 \\
\hline \multirow{4}{*}{ Age group } & $<20$ & 8 & 1.5 \\
in years & $21-30$ & 289 & 55.6 \\
& $31-40$ & 200 & 38.5 \\
& $41-50$ & 20 & 3.8 \\
& $>50$ & 3 & 0.6 \\
\hline \multirow{5}{*}{ Ethnicity } & Brahmin Chhetri & 192 & 36.9 \\
& Madhesi & 19 & 3.7 \\
& Dalit & 30 & 5.8 \\
& Newar & 167 & 32.1 \\
& Other Janajati & 112 & 21.5 \\
\hline
\end{tabular}

Mean volume of semen was $2.48 \pm 0.917$ (ranges 0.2 - 6.0) $\mathrm{ml} ; 36(6.9 \%)$ had hypospermia; and mean sperm concentration was $35.45 \pm 26.68$ (range $=0-$ 150) $\times 10^{6}$ per ml. The most common abnormality was asthenozoospermia followed by azoospermia and oligoasthenozoospermia; and leukocytospermia was in $58(11.1 \%)$ of semen sample. [Table-2]

Table-2: Distribution of abnormal semen parameters

\begin{tabular}{lcc}
\hline Semen abnormalities & $\mathrm{N}$ & $\%$ \\
\hline Asthenozoospermia & 90 & 39.3 \\
Azoospermia & 66 & 28.8 \\
Oligoasthenozoospermia & 41 & 17.9 \\
Oligozoospermia & 20 & 8.7 \\
Oligoasthenoteratozoospermia & 8 & 3.5 \\
Teratozoospermia & 4 & 1.8 \\
\hline
\end{tabular}

After excluding 66 cases of azoospermia, we analyzed and compared normozoospermic and oligozoospermic male partners with different semen parameters. There were statistical differences in parameters like mean age of infertile male partners, total sperm concentration, progressive motility and total immotility of oligozoospermic male partners and normozoospermic male partners, which was significant $(p<0.005)$. But there were no significant differences in total semen volume of both group [Table-3] .

Table-3: Comparison of semen parameters between normozoospermia and oligozoospermia

\begin{tabular}{lccc}
\hline & $\begin{array}{c}\text { Normospermia } \\
\text { Mean } \pm \text { SD } \\
(95 \% \mathrm{CI})\end{array}$ & $\begin{array}{c}\text { Oligopsermia } \\
\text { Mean } \pm \text { SD } \\
(95 \% \mathrm{CI})\end{array}$ & $\begin{array}{c}\mathrm{P}- \\
\text { val- } \\
\text { ue }\end{array}$ \\
\hline Volume & $2.5 \pm 0.9$ & $2.4 \pm 1.0$ & 0.34 \\
Total count & $(2.4-2.6)$ & $(2.1-2.6)$ & \\
& $46.6 \pm 21.7$ & $7.0 \pm 3.8$ & 0.00 \\
Progressive & $(44.4-48.8)$ & $(6.1-7.9)$ & \\
motility & $(47.2 \pm 23.5$ & $19.4 \pm 22.4$ & 0.00 \\
Immotility & $32.7 \pm 20.2$ & $(14.0-24.8)$ & \\
& $(30.7-34.8)$ & $55.5 \pm 26.9$ & 0.00 \\
Age & $30.3 \pm 5.2$ & $28.0-69.0)$ & \\
& $(29.8-30.9)$ & $(27.9-30.0)$ & \\
\hline
\end{tabular}

$p<0.05$; Confidence Interval (CI)

\section{DISCUSSION}

This study showed the prevalence of primary infertility as $78.5 \%$. In a study done by SN Aulia et $\mathrm{al}^{6}$ showed $88.7 \%$ of men with primary infertility and $11.3 \%$ of men with secondary infertility but a Nepalese study by Subedi et $\mathrm{al}^{\mathrm{T}}{ }^{0}$ showed predominance of secondary infertility $(56.56 \%)$.

We found abnormal semen parameter in 229 (44 $\%)$ with most common abnormality as asthenozoospermia (39.3\%) followed by azoospermia (28.8 $\%$ ) and oligoasthenozoospermia (17.9\%). Adeniji RA et al. ${ }^{19}$ also found common abnoramility of asthenzoospermia (27.8\%), followed by oligospermia (18.9\%) and azoopsermia (6.7\%). Azoosp- 
ermia $(28.8 \%)$ was an important finding in our study and this finding was almost double to the study findings of Diallo MS et al. ${ }^{12}$ in Senegal $(14.5 \%)$ but lesser to the study findings of Pant PR in Nepal $(38.9 \%){ }^{13}$

Azoospermia may be related to obstruction of male reproductive tract or defective production. Sperm concentration may not be an only responsible parameter in male infertility, other parameters like motility, semen viscosity, semen volume, and morphology may also be the important parameters for male factor infertility.

The mean sperm concentration for normazoospermic and oligozoospermic group was $46.6 \pm 21.7$ and $7.0 \pm 3.8$ respectively while the mean percentage of progressive motility is $47.2 \pm 23.5$ in normozoospermia and $19.4 \pm 22.4$ in oligozoospermia. Both these results were comparable to the the study findings of Abimibola $\mathrm{N}$ in Nigeria. ${ }^{9}$

The mean ejaculated semen volume for normozoospermic and oligozoospermic group was $2.5 \pm 0.9$ and $2.4 \pm 1.0$ respectively. In both normozoospermic and oligospermic group, semen volume was normal. Out of 520 male partner of infertile couple, $92.1 \%$ had normospermia, $6.9 \%$ had hypospermia and $1 \%$ had hyperspermia. In a study done by Butt $\mathrm{F}^{14}$ in Pakistan also showed normal semen volume for both group with $2.9 \pm 1.35$ for normoazoopsermia and $2.05 \pm 2.0$ for oligozoospermic group.

In our study, majority of semen abnormality was observed in Brahmin-Chhetri ethnic group (35.8\%) followed by that in Newar ethnic (29.3\%). Though the percentage was little different, study done by Pant PR ${ }^{13}$ also showed half of the male factor infertility in Brahmin-chhetri (50\%) followed by that in Newar ethnic (18.2\%). But this finding may have sampling bias because of non-uniform demographic representation.

Results from different studies on semen parameters in infertile couple were conflicting and it may be due to studies carried out in different geographical set up. These variations could also be due to environmental, cultural and socio-economic status of the people, mostly in developing countries. ${ }^{15}$ Hence, further study is required to explain the semen parameters abnormalities in infertile male and its causes in Nepalese context. Study done by Lamichhane $\mathrm{B}$ et $\mathrm{al}^{16}$ also concluded that semen parameters of fertile male were lower than that stated in WHO reference value, $2010 .^{7}$

Limitation of study: This study only demonstrated the abnormality in semen parameters of male factor infertility and did not explain the possible etiologies and/or risk factors for these semen abnormalities. Hence, further study is required to explain the causes of male factor infertility which will ultimately help in managing the male infertility cases. Proportionate representation was not assured for ethnic group distribution.

\section{CONCLUSIONS}

Asthenzoospermia, azoospermia and oligoasthenzoospermia are major factors for contributing male infertility.

\section{REFERENCES}

1. Practice Committee of the American Society for Reproductive Medicine. Definitions of infertility and recurrent pregnancy loss: a committee opinion. Fertil Steril. 2013;99:63.

2. Kumar N, Singh AK. Trends of male factor infertility, an important cause of infertility: A review of literature. J Hum Reprod Sci. 2015;8:191-6.

3. Inhorn MC, Patrizio P. Infertility around the globe: New thinking on gender, reproductive technologies and global movements in the 21st century. Hum Reprod Update. 2015;21(4):41126.

4. Agarwal A, Mulgund A, Hamada A, Chyatte MR. A unique view on male infertility around the globe. Reprod Biol Endocrinol. 2015;13:37.

5. Franken DR, Oehninger S. Semen Analysis and Sperm Function Testing. Asian J Androl. 2012;14,6-13.

6. Aulia SN, Lestari SW, Pratama G, Harzief AK, Sumapraja K, Hestiantoro A, et.al. The pattern of abnormalities on sperm analysis: A study of 1186 infertile male in Yasmin IVF clinic Jakarta J Phys Conf Ser. 2017;884.

7. World Health Organization Press. WHO laboratory manual for the Examination and processing of human semen. $5^{\text {th }}$ ed. 2010.

8. Peter AO, Temi AP, Olufemi AP, Simidele OM, Adeniran AS, Amos IA. Pattern of Semen Parameters and Factors Associated with Infertility in Male Partners of Infertile Couples in Nigeria. Andrology (Los Angel). 2016;5(1):161 -7 .

9. Abimibola N, Oghenevware U.Semen Quality of Male Partners of Infertile Couples Attending Fertility Clinics in Delta State University Teaching Hospital, Oghara, Delta State, Nigeria. J Androl Gynaecol. 2017;5(1):4

10.Subedi S, Lamichhane S, Chhetry M. Study of Infertile Couples Attending a Teaching Hospital in Eastern Nepal. J Nepal Med Assoc. 2016;55(203):22-5.

11.Adeniji RA, Olayemi O, Okunlola MA, Aima- 
khu CO. Pattern of semen analysis of male partners of infertile couples at the University College Hospital, Ibadan. West African J Med. 2003;22(3):243-5.

12.Diallo MS, Diallo AS, Fotso P, Diallo Y, BabacarDiao B, Faye O. Semen Abnormality Patterns and Parameters in Male Partners of Infertile Couples in Dakar (Senegal). Open J Urol. 2015;5:155-60.

13.Pant PR. Abnormal Semen Parameters among Men in Infertile Couples. Nep J Obstet Gynaecol. 2013;8(1):53-5.
14. Butt F, Akram N. Semen analysis parameters: Experiences and insight into male infertility at a tertiary care hospital in Punjab. J Pak Med Assoc. 2013;63:58-62.

15.Leke RJ, Oduma JA, Bassol-Mayagoitia S, Bacha AM, Grigor M. Regional and geographical variation in infertility: Effects of environmental, cultural and socioeconomic factors. Environ Health Perspect. 1993;101(2):73-80.

16.Lamichhane B, Baral JR, Manadhar R, Shrestha A. Semen Parameters of Fertile Men Attending Tribhuvan University Teaching Hospital. Nep J Obstet Gynaecol. 2014;9(2):87-91. 